\title{
Abnormal Appearance of Spinal Hemangioma Mimicking Metastasis in Bone Scintigraphy and SPECT-CT: Case Report
}

Jomon Raphael ${ }^{1,2 *}$, Julie Hephzibah'², Sunithi Mani ${ }^{3}$, Nylla Shanthly ${ }^{2}$ and Regi Oommen ${ }^{2}$

${ }^{1}$ Department of Oncology, Amala Cancer Center Thrissur, India

${ }^{2}$ Department of Nuclear Medicine, Christian Medical College Vellore, India

${ }^{3}$ Department of Radiology, Christian Medical College Vellore, India

\begin{abstract}
Study design: Case reports of abnormal appearance of hemangioma in thoracolumbar spine in bone scintigraphy.

Objective: To report an unusual presentation of spinal hemangioma mimicking metastasis in bone scintigraphy and SPECT-CT.

Summary of back ground data: Spinal hemangiomas are usually incidental findings. Most of them are asymptomatic and bone scintigraphy will be normal in majority of them. In the back ground of an underlying malignancy, an abnormal hot spot in bone scan always arouse a high suspicion of bone metastasis.

Methods: Two middle aged ladies, treated for carcinoma cervix and carcinoma breast respectively, were undergoing regular follow ups. One patient had complaints of back pain on and off and her bone scan showed abnormal increase in tracer uptake in L1 vertebra suspicious of metastasis. Second lady had suspected intra abdominal metastatic disease and her bone scan showed abnormal increase in tracer uptake in thoracolumbar spine mimicking metastasis.

Results: Both patients underwent further detailed evaluations and MRI study of spine was reported as hemangioma and PET-CT ruled out the possibilities of recurrent or metastatic malignancy. During further follow up, both patients were disease free.

Conclusion: Hemangioma of spine appearing as a hot spot in bone scan is rare. In the back ground of a malignancy, a 'hot' lesion can be studied better with metabolic imaging with PET - CT which could dispel the suspicion of a metastatic focus quite clearly. MRI could also give a diagnostic clue.
\end{abstract}

Keywords: Bone scan; Hemangioma; Photopenic area; Metastasis

\section{Introduction}

Haemangioma of spine is a benign condition. The common sites of involvement are lower thoracic and upper lumbar vertebrae. It is usually asymptomatic and is more frequently seen in women. The peak incidence is in fourth decade and is usually multiple in up to $1 / 3$ of cases. In general, most of them occur in the medullary cavity of bone. Microscopically, there is hamartomatous proliferation of vascular tissue. They are classified as cavernous, capillary, arteriovenous and venous types. Haemangiomas of spine are usually capillary type and in skull, are cavernous.

Here we present a patient treated for carcinoma cervix, who complained of back pain. While undergoing evaluation for bone metastases she was found to have a suspicious lesion in L1 vertebra in bone scintigraphy (BS) and Single Photon Emission Computed Tomography-Computed Tomography ((SPECT-CT). This was later confirmed as non-malignant in PET-CT and hemangioma in magnetic resonance imaging (MRI) scan.

\section{Materials and Methods}

Two cases were selected from the patients came for BS in our department. After noticing the abnormal findings in BS further investigation been done under corresponding clinical departments in our institute. Routine informed consent been taken for all necessary investigations and treatment.

\section{Case 1}

A 46 years old lady, who was evaluated in a primary care hospital for bleeding per vagina, underwent abdominal hysterectomy and later the histopathology of surgical specimen was reported as carcinoma cervix FIGO stage I b. She came to our hospital for further evaluation and management. She underwent external radiotherapy and brachytherapy.

During the first follow up at 6 months, she complained of back ache and underwent a Technetium-99m methylene diphosphonate BS to rule out bone metastasis. Planar images of BS showed increased tracer uptake in L1 vertebra (Figure 1a) and SPECT-CT fusion images (Figures $1 \mathrm{~b}$ and $1 \mathrm{c}$ ) revealed increased tracer uptake in L1 vertebral body corresponding to a osteolytic lesion in CT images.

MRI scan done to evaluate the status of local disease in pelvis, demonstrated the lesion in L1 body, showing characteristic features of hemangioma (Figure 2).

MRI showed the lesion to be well defined and hyperintense on both

*Corresponding author: Jomon Raphael, Department of Oncology, Amala cancer center Thrissur, India, Tel: +91-9544316325; Fax: 0487 2307969; E-mail: joeraphael@gmail.com

Received August 12, 2013; Accepted September 10, 2013; Published September 25, 2013

Citation: Raphael J, Hephzibah J, Mani S, Shanthly N, Oommen R (2013) Abnormal Appearance of Spinal Hemangioma Mimicking Metastasis in Bone Scintigraphy and SPECT-CT: Case Report. J Nucl Med Radiat Ther S6: 016. doi:10.4172/2155-9619.S6-016

Copyright: $\odot 2013$ Raphael J, et al. This is an open-access article distributed under the terms of the Creative Commons Attribution License, which permits unrestricted use, distribution, and reproduction in any medium, provided the original author and source are credited. 
Citation: Raphael J, Hephzibah J, Mani S, Shanthly N, Oommen R (2013) Abnormal Appearance of Spinal Hemangioma Mimicking Metastasis in Bone Scintigraphy and SPECT-CT: Case Report. J Nucl Med Radiat Ther S6: 016. doi:10.4172/2155-9619.S6-016

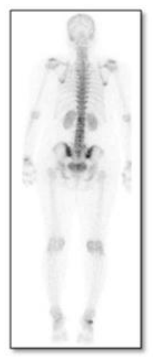

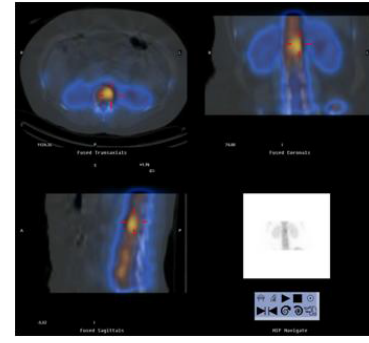

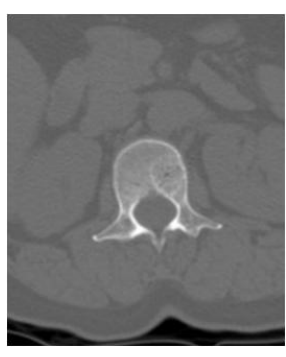

c
Figure 1: a) Planar images of bone scan showing increased tracer uptake in L1 vertebra b) SPECT-CT fusion images revealed increased tracer uptake in L1 vertebral body corresponding to a osteolytic lesion in CT images C) CT section in bone window at L1 vertebra showing a well defined lesion with peripheral sclerotic rim and central 'polka dot sign'.

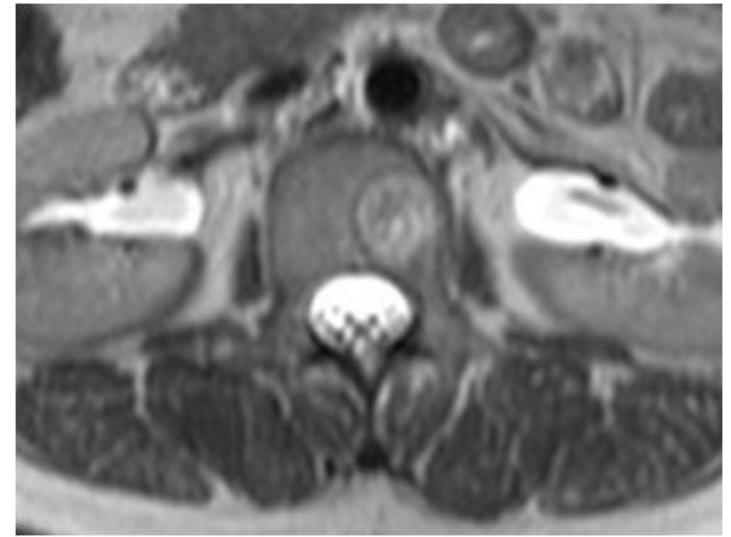

Figure 2: T2W axial section showing the T2 hypointense peripheral sclerotic rim and central hyperintensity.
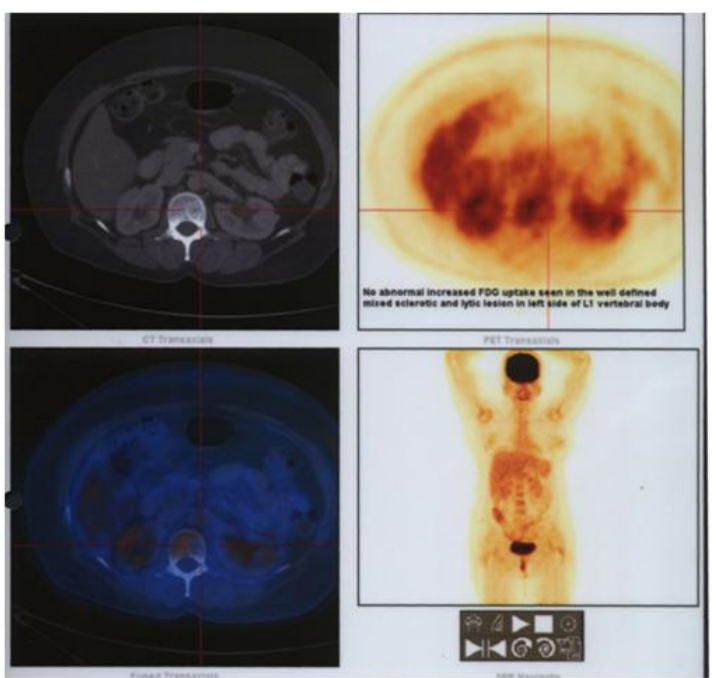

Figure 3: PET-CT showed no evidence of increased metabolic activity in L1 vertebra and a osteolytic area in L1 vertebral body.

T2 and T1W imaging and hyperintense on STIR images as well. On $\mathrm{T} 2 \mathrm{~W}$ images, in addition, there were multiple hypointense dots within. These features are considered typical for hemangioma.

However, as the patient had persistent back ache and BS showed findings in favor of metastasis in L1 vertebra, a positron emission tomography (PET)-CT was done to identify the nature of the lesion. PET-CT showed no evidence of increased metabolic activity in L1 vertebra and an osteolytic area in L1 vertebral body (Figure 3), thus excluding a metastatic deposit and confirming the diagnosis of hemangioma.

\section{Case 2}

A 54 year old lady diagnosed to have carcinoma left breast, underwent surgery, radiotherapy and chemotherapy and had come for follow up. Clinical examination revealed hepatomegaly and left ovarian mass, and BS done in view of suspicious bone metastases, showed abnormal increase in tracer uptake in the left $2^{\text {nd }}$ rib and thoracolumbar vertebrae (Figure 4).

She underwent further evaluation and her intraabdominal lesions were found to be benign. Her CT thorax showed multiple vertebral and rib hemangiomas (Figure 5). She also underwent a PET CT scan which ruled out skeletal metastases.

\section{Results}

Both patients were kept on regular follow up; first patient was reviewed at 6 months, and the second patient at 2 years. Both the patients were found to be disease free.

\section{Discussion}

Hemangioma of spine usually presents as an asymptomatic condition. Because of this reason, in most situations, the diagnosis will be incidental. Appearance of hemangioma in BS has been discussed well in literature. A case series on BS reported 'normal bone scan' in hemangioma of spine [1]. A comparative study between SPECT-CT and MRI spine in diagnosing spine hemangioma showed no specific diagnostic findings noticed in SPECT-CT. Another case report of a patient detected to have haemangioma in lower thoracic spine demonstrated photopenic area on BS [2]. There are situations in which hemangioma of the bone was detected in triphase bone scan [3].

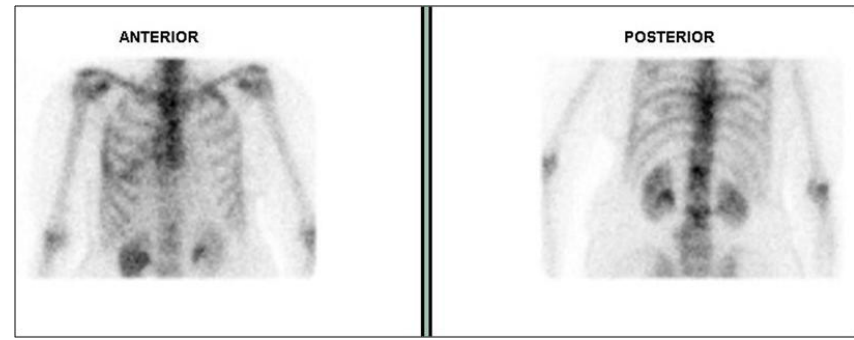

Figure 4: Bone scan showing abnormal increase in tracer uptake in the left $2^{\text {nd }}$ rib and thoracolumbar vertebrae.

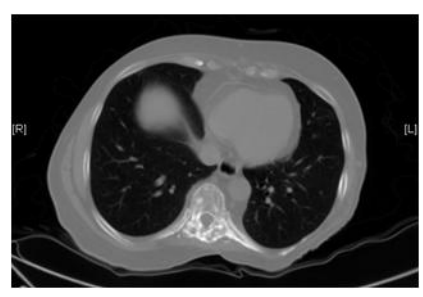

a

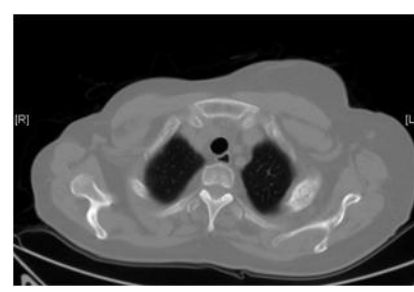

b
Figure 5: CT thorax showed multiple vertebral and rib hemangiomas. 
Citation: Raphael J, Hephzibah J, Mani S, Shanthly N, Oommen R (2013) Abnormal Appearance of Spinal Hemangioma Mimicking Metastasis in Bone Scintigraphy and SPECT-CT: Case Report. J Nucl Med Radiat Ther S6: 016. doi:10.4172/2155-9619.S6-016

Based on these evidences hemangioma of the spine in BS will mostly be negative for increased tracer uptake or it may be photpenic in rare occasions. Thus, BS showing abnormal tracer accumulation in vertebrae in delayed images, most often rules out hemangioma.

Here in the first case, paraaortic nodal metastases, or lumbar spine metastases/infiltration were considered, as these are common sequeale in patients with carcinoma cervix [4]. Increased lumbar spine uptake and co-registered SPECT-CT images localizing the tracer uptake in vertebral body, point towards the possibility of a metastasis. MRI scan showed T1 and T2 hyperintense lesion with central T2 hypointense foci, which are typically described in hemangioma [5]. PET scan show metabolically inactive lesion [6] and corresponding CT slices show 'polka dot sign' $[7,8]$. The reason for increased tracer uptake in hemangioma in BS is not very clear. Calcification in old hemangiomas or sclerotic changes in involved bone are few possibilities. In the back ground of a proven malignancy these findings always arouse suspicions.

In the second case, lady with carcinoma breast had suspicious lesions in abdomen during follow up evaluation, and increased tracer uptake in spine and ribs in BS. Carcinoma breast is one of the commonest malignancies with sclerotic metastases in skeletal system [9]. CT scan in this situation clarified the doubts and a PET scan proved the non malignant nature of the skeletal as well as abdominal lesions. Both these cases also proved the ability of PET-CT in differentiating benign lesions like hemangioma of spine from malignant conditions.

\section{Conclusion}

Hemangioma of spine appearing as a hot spot in BS is rare. In patients with malignancies which are well known to develop bone metastases, metabolic imaging with PET-CT could dispel the suspicion of metastatic foci quite clearly. MRI could also give a diagnostic clue.

\section{References}

1. Han BK, Ryu JS, Moon DH, Shin MJ, Kim YT, et al. (1995) Bone SPECT imaging of vertebral hemangioma correlation with MR imaging and symptoms. Clin Nucl Med 20: 916-921.

2. Gerard PS, Wilck E (1992) Spinal hemangioma. An unusual photopenic presentation on bone scan. Spine (Phila Pa 1976) 17: 607-610.

3. Yapar AF, Yapar Z, Kibar M, Barutcu O, Akpinar S (1999) Incidental detection of a vertebral body hemangioma on three-phase bone scintigraphy. Clin Nucl Med 24: 999-1001.

4. Fisher MS (1980) Lumbar spine metastasis in cervical carcinoma: a characteristic pattern. Radiology 134: 631-634

5. Asem Hiari, Bassam Nawaiseh, Hesham Jaber (1998) Spine Metastasis in Cervical Carcinoma: A review. Eastern Mediterranean Health Journal 4: 149155

6. Bybel B, Raja S (2003) Vertebral hemangiomas on FDG PET scan. Clin Nuc Med 28: 522-523.

7. Laredo JD, Reizine D, Bard M, Merland JJ (1986) Vertebral hemangiomas: radiologic evaluation. Radiology 161: 183-189.

8. Persaud T (2008) The polka-dot sign. Radiology 246: 980-981.

9. James JJ, Evans AJ, Pinder SE, Gutteridge E, Cheung KL, et al. (2003) Bone metastases from breast carcinoma: histopathological - radiological correlations and prognostic features. $\mathrm{Br} \mathrm{J}$ Cancer 89: 660-665.
This article was originally published in a special issue, Cancer Radiation Therapy handled by Editor(s). Dr. Xin Chen, University of Arkansas for Medical Sciences, USA 